Research Article

\title{
Assessment of Prevalence, Drug Utilization Pattern and Potential Drug-Drug Interactions among Hepatic Impairment Patients
}

\section{Dr. Natish Belbase*, Dr. Dinesh Raj Neupane, Dr. Rini Ponnachan, Dr. Jaiji Thomas, Dr. Ramesh Basnet, Dr. Asmit Acharya Pharm D, Department of Pharmacy Practice, SCS College of Pharmacy, Harapanahalli, Karnataka, India.}

*Corresponding author's E-mail: natishbelbase@gmail.com

Received: 12-05-2021; Revised: 23-06-2021; Accepted: 30-06-2021; Published on: 15-07-2021.

\section{ABSTRACT}

The majority of drugs are metabolised in liver and are known to be hepatotoxic. So, the Drug Utilization Evaluation (DUE) studies become potential tool in hepatic impairment patient to ensure drugs are used appropriately, safely and effectively in order to improve overall health of patient. Drug-Drug Interactions are major cause of concern among hepatic impairment patients due to co-morbidity conditions and wide class of drugs they receive. The clinical result of DDI may manifest as synergism, antagonism or idiosyncratic. This study is aimed to generate data on drug utilization pattern and to assess the prevalence of potential drug-drug interactions (pDDIs) among hospitalised hepatic impairment patients. A prospective observational study was carried out for six months among inpatients of the medicine department of Chigateri District Hospital, Karnataka, India. Potential drug-drug interactions (pDDIs) were analysed using Lexicomp, Medscape drug interaction checker, Stockley's drug interaction checker. Overall 135 patients were enrolled the study. In this study, $80.68 \%$ patients were male. The most common affected age group was 40-59 years. Alcoholic liver disease (46.66\%) and chronic liver disease $(27.40 \%)$ were the most prevalent hepatic condition. Anemia and portal hypertension were the most likely associated comorbidities. Out of 1097 drugs, 569 drugs were used specifically for hepatic impairment. Diuretics (23.02\%) were the most frequently prescribed drugs followed by gallstone dissolution agents (18.27\%). Total of 264 pDDIs, were identified, of which $76(28.78 \%)$ were minor, $180(68.18 \%)$ were moderate and $8(3.03 \%)$ were major. Potential DDIs were significantly higher in patients taking $\geq 9$ medicines $(63.63 \%)$, hospitalization $\geq 7$ days $(67.64 \%)$ and with one co-morbidity conditions (43.18\%). Pharmacodynamic interaction 197 (74.62\%) was observed more than that of pharmacokinetic interactions 67(25.37\%). The prevalence of alcoholic liver disease in this study was reported the most. Antibiotics were the most prescribed drugs, so the consequences of hepatotoxicity and antibiotic resistance is high. Hence, rational use of drug should be strictly followed. Also, this study illustrated a high prevalence of pDDIs among males, number of prescribed drugs, length of hospital stay and co-morbidity conditions.

Keywords: Drug-Drug Interactions(pDDIs), Hepatic Impairment, Drug Utilization Pattern, Prevalence.

QUICK RESPONSE CODE $\rightarrow$

DOI:

10.47583/ijpsrr.2021.v69i01.034

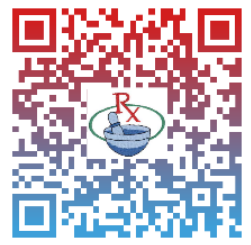

DOI link: http://dx.doi.org/10.47583/ijpsrr.2021.v69i01.034

\section{INTRODUCTION}

C hronic Liver Diseases (CLD) are the set of diseases characterised by the decreased hepatic functions as a result of chronic inflammation of the liver. At the most advanced stage CLDs progresses to cirrhosis, a condition in which healthy liver tissue is destroyed and replaced by scar tissue. This build up of scar tissue can eventually lead to liver dysfunction and complications of portal hypertension and hepatocellular carcinoma ${ }^{1}$. Recent estimates suggest that chronic liver disease is a major cause of morbidity and mortality, with 2 million individuals dying of liver disease each year, worldwide ${ }^{2}$.

The World Health Organization (WHO) defines drug utilization research as "the marketing, distribution, prescription and use of drugs in a society, with special emphasis on the resulting medical, social and economic consequences" $^{\prime 3}$. Moreover, drug utilization research studies conducted in the inpatients settings is a useful tools for obtaining valuable information about the drugs prescribing trends, quality of drugs use, efficacy of drug use and cost-effectiveness of hospital formularies. Thus, drug utilization studies helps in determining the rationality of drug use and developing strategies based on various guidelines to utilize health resources in the most effective manner ${ }^{4}$.

Hepatic impairment patients are usually present with comorbidities and polypharmacy which increases the risk of potential drug interactions (pDDIs). One of the specific types of Adverse Drug Events (ADE) is drug-drug interaction that occur when the pharmacological effect of a drug is altered by another drug that is taken ${ }^{5}$. DDIs can be classified based on the severity and mechanism by which drugs interact with each other. Based on their severity, DDIs can be major, moderate and mild. Major DDIs are potentially life threatening or may cause prolonged or permanent damage. Moderate DDIs can cause deterioration in patient's health condition and may require medical intervention. Minor DDIs are usually not serious and do not require change in therapy ${ }^{6}$. Furthermore, DDIs can also be classified as 
pharmacokinetic and pharmacodynamics based on the mechanism of how drugs interact with each other. Pharmacokinetic interactions occur when there are alteration in absorption, distribution, metabolism and elimination. Similarly, the clinical result of pharmacodynamics interactions may manifest as antagonism and synergism ${ }^{7}$. Therefore, this study sought to determine the type, prevalence and characteristics of pDDIs among hepatic impairment patients and to analyse the rationality of the prescriptions.

\section{MATERIALS AND METHODS}

Study Site: The study was conducted in the medicine department of Chigateri District Hospital, Davangere, India (Tertiary care teaching hospital)

Study Design: The study was Prospective, observational study.

Sample Size: Total 135 patients were enrolled in the study.

Study Duration: The study was conducted for a period of 6 months.

Source of Data: Data was collected from case sheet of inpatients from the General Medicine Department.

\section{Study Criteria}

\section{Inclusion criteria:}

- $\quad$ All the patients admitted to general medicine ward diagnosed with any type of hepatic diseases

- Patients of either sex

- $\quad$ Patients with age above 18 years

\section{Exclusion criteria}

- $\quad$ Out patients

- Paediatric and pregnant women

- Patients with incomplete or missing data

- $\quad$ Patient with underlying diseases like HIV, AIDS.

\section{METHODOLOGY}

This is a prospective observational study conducted in Chigateri District Hospital, Davanagere, India. The study was approved by the hospital ethical committee. Patients were enrolled study on basis of inclusion and exclusion criteria. All the relevant data was collected in specifically designed data collection form. The pooled data were analysed for further investigation on prescribing pattern in hepatic impairment patients and prevalence of pDDIs among hepatic impairment patients. Potential drug-drug interactions were evaluated by using Lexicomp, Medscape interaction checker, Stockley's drug interaction. Data were analysed in frequency and percentage using MS Excel.

\section{RESULTS}

In our study, the medical and medication profiles of 135 hospitalised hepatic impairment patients were evaluated and monitored in terms of Drug Utilization Evaluation (DUE) and Potential Drug-Drug Interactions (DDIs). Majority of the study participants were male accounting for $113(83.70 \%)$ whereas female accounted for 22(16.29\%). Out of the 135 patient's prescription analysed, the common prevalent hepatic impairment was alcoholic liver disease $(n=63,46.66 \%)$ and chronic liver disease $(n=37,27.40 \%)$ and the least common were drug induced hepatitis $(n=4,2.96 \%)$, alcoholic hepatitis $(n=4,2.96 \%)$ and cholelithiasis $(n=4,2.96 \%)$. The complete information is illustrated in (Table 2).

Out of the 135 patients, around 63(46.66\%) patients were diagnosed without comorbidities and $72(53.33 \%)$ patients were diagnosed with comorbid conditions. Amongst patients diagnosed with comorbid conditions, patients with one comorbid accounted for $51(37.77 \%)$ and patients with two comorbidities accounted for $21(15.55 \%)$. Anemia $(n=29)$ and portal hypertension $(n=23)$ being the common comorbidities (Table 3).

Total of 1097 drugs were prescribed, of which 569 drugs were prescribed specifically for hepatic impairment. Drugs like diuretics were most frequently prescribed $131(23.02 \%)$ followed by gallstone dissolution agents 104(18.27\%) and Laxatives 73(12.82\%). The anti-viral drug $1(0.17 \%)$ was the least prescribed drug (Table 4$)$. Whereas total of 528 drugs prescribed were non-hepatospecific. Among non-hepatospecific drugs, the most widely prescribed drugs was antibiotics $133(25.18 \%)$ followed by anti-ulcer drugs $124(23.48 \%)$ and vitamin supplements 91(17.23\%) (Table 5).

Table 6 depicts the exposure of patients to all types of pDDIs stratified with respect to patient's characteristics. DDIs were more frequent in male as compared to female. Additionally, pDDls were more commonly observed in patients aged 40-59 years, hospital stay of $\geq 7$ days, taking $\geq 9$ medicines. Also, DDIs were more frequent in patients diagnosed with one comorbidity $114(43.18 \%)$. Out of the 264 pDDIs, about 76(28.78\%) were minor, 180(68.18\%) were moderate and $8(3.03 \%)$ were major (Table 7$)$. A total of $67(25.37 \%)$ pDDIs were due to pharmacokinetic interactions and $197(74.62 \%)$ pDDIs were due to pharmacodynamics interactions (Table 8). Out of 67 pharmacokinetics interactions, metabolism interactions $52(77.61 \%)$ comprised the most followed by absorption $8(11.94 \%)$, excretion 5(7.46\%) and distribution 2 (2.98\%) (Table 9). Similarly, out of 197 pharmacodynamic interactions, synergistic interactions 101(51.26\%) were frequently observed as compared to antagonistic interactions 96(48.73\%) (Table 10). From the most frequently occurring pDDIs, drug interaction between Furosemide and Ceftriaxone (Minor) occurred in about 62 prescriptions whereas drug interaction between Furosemide and Spironolactone (Moderate) accounted for 51 prescriptions (Table 11). 
Table 1: Gender wise distribution of patients

\begin{tabular}{|l|c|c|}
\hline Gender & Number of patients (n) & Percentage (\%) \\
\hline Male & 113 & $83.70 \%$ \\
\hline Female & 22 & $16.29 \%$ \\
\hline Total & 135 & 100 \\
\hline
\end{tabular}

Table 2: Prevalence of various Hepatic Impairments

\begin{tabular}{|l|l|c|}
\hline S.no. & Diseases & $\begin{array}{c}\text { Number of } \\
\text { patients, } \mathbf{n}(\%)\end{array}$ \\
\hline 1. & Chronic Liver Disease & $37(27.40 \%)$ \\
\hline 2. & Alcoholic Liver Disease & $63(46.66 \%)$ \\
\hline 3. & Pancreatitis & $5(3.70 \%)$ \\
\hline 4. & Hepatic Encephalopathy & $\mathbf{7 ( 5 . 1 8 \% )}$ \\
\hline 5. & Non-Alcoholic Hepatitis & $4(2.96 \%)$ \\
\hline 6. & Alcoholic Hepatitis & $4(2.96 \%)$ \\
\hline 7. & Hepatocellular Carcinoma & $5(3.70 \%)$ \\
\hline 8. & Drug Induced Hepatitis & $4(2.96 \%)$ \\
\hline 9. & Cholelithiasis & $6(4.44 \%)$ \\
\hline & Total & $\mathbf{N = 1 3 5 ( 1 0 0 \% )}$ \\
\hline
\end{tabular}

Table 3: Occurrences of Comorbidities among Hepatic Impairment patients

\begin{tabular}{|c|c|c|c|c|}
\hline Hepatic Diseases & \multicolumn{2}{|c|}{ One comorbidity, n (\%) } & \multicolumn{2}{|c|}{ Two comorbidities, n (\%) } \\
\hline \multirow[t]{7}{*}{ Chronic Liver Disease } & CLD+Anemia & $2(1.48 \%)$ & $\mathrm{CLD}+\mathrm{HE}+\mathrm{PH}$ & $2(1.48 \%)$ \\
\hline & $\mathrm{CLD}+\mathrm{HE}$ & $3(2.22 \%)$ & CLD+Pancreatitis+PVT & $1(0.74 \%)$ \\
\hline & $\mathrm{CLD}+\mathrm{HBV}$ & $1(0.74 \%)$ & $\mathrm{CLD}+\mathrm{HBV}+\mathrm{PH}$ & $1(0.74 \%)$ \\
\hline & CLD+Ascites & $5(3.70 \%)$ & $\mathrm{CLD}+\mathrm{HBV}+$ Anemia & $3(2.22 \%)$ \\
\hline & CLD+CKD & $2(1.48 \%)$ & $\mathrm{CLD}+\mathrm{PH}+$ Anemia & $2(1.48 \%)$ \\
\hline & $\mathrm{CLD}+\mathrm{PH}$ & $10(7.40 \%)$ & \multirow[t]{2}{*}{ Total } & \multirow[t]{2}{*}{$9(6.66 \%)$} \\
\hline & Total & $23(17.03 \%)$ & & \\
\hline \multirow[t]{9}{*}{ Alcoholic Liver Disease } & ALD+Pancreatitis & $5(3.70 \%)$ & ALD+Psoriasis+Anemia & $1(0.74 \%)$ \\
\hline & ALD+Anemia & $10(7.40 \%)$ & $\mathrm{ALD}+\mathrm{HE}+\mathrm{Anemia}$ & $2(1.48 \%)$ \\
\hline & $A L D+C K D$ & $2(1.48 \%)$ & $\mathrm{ALD}+\mathrm{HE}+\mathrm{PH}$ & $2(1.48 \%)$ \\
\hline & $A L D+R V D$ & $1(0.74 \%)$ & ALD+PH+Anemia & $4(2.96 \%)$ \\
\hline & $\mathrm{ALD}+\mathrm{PH}$ & $3(2.22 \%)$ & \multirow{5}{*}{ Total } & \multirow{5}{*}{$9(6.66 \%)$} \\
\hline & ALD+Gastritis & $2(1.48 \%)$ & & \\
\hline & ALD+Cholelithiasis & $1(0.74 \%)$ & & \\
\hline & ALD+HRS & $1(0.74 \%)$ & & \\
\hline & Total & $25(18.51 \%)$ & & \\
\hline \multirow[t]{3}{*}{ Hepatocellular Carcinoma } & $\mathrm{HCC}+\mathrm{PH}$ & $1(0.74 \%)$ & & \\
\hline & HCC+Anemia & $2(1.48 \%)$ & & \\
\hline & Total & $3(2.22 \%)$ & & \\
\hline \multirow[t]{2}{*}{ Alcoholic Hepatitis } & & & $\mathrm{AH}+\mathrm{AGE}+\mathrm{Anemia}$ & $1(0.74 \%)$ \\
\hline & & & Total & $1(0.74 \%)$ \\
\hline \multirow[t]{2}{*}{ Drug Induced Hepatitis } & & & DIH+RVD+Anemia & $2(1.48 \%)$ \\
\hline & & & Total & $2(1.48 \%)$ \\
\hline Total [n (\%)] & $51(37.77 \%)$ & & $21(15.55 \%)$ & \\
\hline \multicolumn{4}{|c|}{ Only hepatic diseases (without co-morbidities } & $63(46.66 \%)$ \\
\hline \multicolumn{4}{|l|}{ Total } & $\mathrm{N}=135(100 \%)$ \\
\hline
\end{tabular}

CLD: Chronic Liver Disease; ALD: Alcoholic Liver Disease; CKD: Chronic Kidney Disease; PH: Portal Hypertension; HE: Hepatic Encephalopathy; PVT: Portal Vein Thrombosis; HRS: Hepatorenal Syndrome; RVD: Retro Viral Disease; HCC: Hepatocellular Carcinoma; HBV: Hepatitis B Virus ; DIH: Drug-Induced Hepatitis; AH: Alcoholic Hepatitis; AGE: Acute Gastro Enteritis; 
Table 4: Drug Utilization Pattern of Drugs Used Specifically for Hepatic Impairment

\begin{tabular}{|l|l|l|}
\hline S.no. & Class of Drugs & $\begin{array}{l}\text { Number of Drugs, } \\
\mathbf{n}(\%)\end{array}$ \\
\hline 1. & $\begin{array}{l}\text { Gallstone dissolution } \\
\text { agents }\end{array}$ & $104(18.27 \%)$ \\
\hline 2. & Liver protectants & $62(10.89 \%)$ \\
\hline 3. & Laxatives & $73(12.82 \%)$ \\
\hline 4. & $\begin{array}{l}\text { Drugs used to treat } \\
\text { edema (Diuretics) }\end{array}$ & $131(23.02 \%)$ \\
\hline 5. & $\begin{array}{l}\text { Drugs used to treat portal } \\
\text { HTN( } \square \text {-blockers) }\end{array}$ & $45(7.90 \%)$ \\
\hline 6. & Anti-hemorrhagic agents & $59(10.36 \%)$ \\
\hline 7. & Transfusions & $30(5.27 \%)$ \\
\hline 8. & Corticosteroids & $4(0.70 \%)$ \\
\hline 9. & Anti-viral drug & $1(0.17 \%)$ \\
\hline 10. & Antibiotics & $60(10.54 \%)$ \\
\hline & Total & $\mathbf{N = 5 6 9 ( 1 0 0 \% )}$ \\
\hline
\end{tabular}

Table 5: Drug Utilization Pattern of Non-Hepatospecific Drugs

\begin{tabular}{|l|l|l|}
\hline S.no. & Class of Drugs & $\begin{array}{l}\text { Number of Drugs, } \\
\mathbf{n}(\%)\end{array}$ \\
\hline 1. & Analgesics & $56(10.60 \%)$ \\
\hline 2. & Antibiotics & $133(25.18 \%)$ \\
\hline 3. & Anti-Ulcer agents & $124(23.48 \%)$ \\
\hline 4. & Anti-emetics & $35(6.62 \%)$ \\
\hline 5. & Anti-diarrheal & $8(1.51 \%)$ \\
\hline 6. & Anti-convulsant & $19(3.59 \%)$ \\
\hline 7. & Anti-viral drugs & $3(0.56 \%)$ \\
\hline 8. & Vitamin Supplements & $91(17.23 \%)$ \\
\hline 9. & Nebulisation & $6(1.13 \%)$ \\
\hline 10. & Corticosteroids & $4(0.75 \%)$ \\
\hline 11. & Anti-histamines & $6(1.13 \%)$ \\
\hline 12. & Anti-hypertensive Drugs & $5(0.94 \%)$ \\
\hline 13. & Cardiovascular Agents & $4(0.75 \%)$ \\
\hline 14. & Miscellaneous & $34(6.43 \%)$ \\
\hline & Total & $\mathbf{N}=528(100 \%)$ \\
\hline
\end{tabular}

Table 6: General characteristics of study subjects and exposure to all pDDIs

\begin{tabular}{|c|c|c|c|}
\hline \multicolumn{2}{|c|}{ Patient's characteristics } & \multirow{2}{*}{$\begin{array}{l}\text { Patients, n } \\
\text { (\%) } \\
113(83.70 \%)\end{array}$} & \multirow{2}{*}{$\begin{array}{l}\text { Exposure to } \\
\text { all types of } \\
\text { pDDIs, } n(\%) \\
213(80.68 \%\end{array}$} \\
\hline Gender & Male & & \\
\hline & Female & $22(16.29 \%)$ & $51(19.31 \%)$ \\
\hline \multirow[t]{3}{*}{ Age(Years) } & $20-39$ & $61(45.18 \%)$ & $120(45.45 \%)$ \\
\hline & $40-59$ & $66(48.88 \%)$ & $129(48.86 \%)$ \\
\hline & $\geq 60$ & $8(5.92 \%)$ & $15(5.68 \%)$ \\
\hline \multirow{2}{*}{$\begin{array}{l}\text { No. of drugs } \\
\text { on } \\
\text { prescription }\end{array}$} & $<9$ & $44(32.59 \%)$ & $91(34.46 \%)$ \\
\hline & $\geq 9$ & $91(67.40 \%)$ & $168(63.63 \%)$ \\
\hline \multirow{2}{*}{$\begin{array}{l}\text { Hospital } \\
\text { Stays (Days) }\end{array}$} & $<7$ & $45(33.33 \%)$ & $87(32.95 \%)$ \\
\hline & $\geq 7$ & $90(66.66 \%)$ & $177(67.04 \%)$ \\
\hline \multirow[t]{3}{*}{$\begin{array}{l}\text { No. of } \\
\text { Comorbidities }\end{array}$} & $\begin{array}{l}\text { No } \\
\text { Comorbidities }\end{array}$ & $63(46.66 \%)$ & $97(36.74 \%)$ \\
\hline & $\begin{array}{l}\text { One } \\
\text { Comorbidity }\end{array}$ & $51(37.77 \%)$ & $114(43.18 \%)$ \\
\hline & $\begin{array}{l}\text { Two } \\
\text { Comorbidities }\end{array}$ & $21(15.55 \%)$ & $53(20.07 \%)$ \\
\hline
\end{tabular}

Table 7: Distribution of DDIs based on severity

\begin{tabular}{|l|c|c|}
\hline Severity & Number of pDDIs (n) & Percentage (\%) \\
\hline Major & 8 & $3.03 \%$ \\
\hline Moderate & 180 & $68.18 \%$ \\
\hline Minor & 76 & $28.78 \%$ \\
\hline Total & $\mathbf{2 6 4}$ & 100 \\
\hline
\end{tabular}

Table 8: Distribution of DDIs based on its types

\begin{tabular}{|l|c|c|}
\hline Types of DDIs & $\begin{array}{c}\text { Number of } \\
\text { pDDIs (n) }\end{array}$ & $\begin{array}{c}\text { Percentage } \\
\text { (\%) }\end{array}$ \\
\hline Pharmacokinetics & 67 & $25.37 \%$ \\
\hline Pharmacodynamics & 197 & $74.62 \%$ \\
\hline Total & $\mathbf{2 6 4}$ & $\mathbf{1 0 0}$ \\
\hline
\end{tabular}

Table 9: Distribution of DDIs based on Pharmacokinetic Interactions

\begin{tabular}{|l|c|c|}
\hline $\begin{array}{l}\text { Pharmacokinetic } \\
\text { DDIs }\end{array}$ & $\begin{array}{c}\text { Number of } \\
\text { pDDls (n) }\end{array}$ & Percentage (\%) \\
\hline Absorption & 8 & $11.94 \%$ \\
\hline Distribution & 2 & $2.98 \%$ \\
\hline Metabolism & 52 & $77.61 \%$ \\
\hline Excretion & 5 & $7.46 \%$ \\
\hline Total & $\mathbf{6 7}$ & 100 \\
\hline
\end{tabular}


Table 10: Distribution of DDIs based on Pharmacodynamic Interactions

\begin{tabular}{|l|l|c|}
\hline $\begin{array}{l}\text { Pharmacodynamic } \\
\text { DDls }\end{array}$ & $\begin{array}{l}\text { Number of } \\
\text { pDDls (n) }\end{array}$ & Percentage (\%) \\
\hline Synergism & 101 & $51.26 \%$ \\
\hline Antagonism & 96 & $48.73 \%$ \\
\hline Total & $\mathbf{1 9 7}$ & 100 \\
\hline
\end{tabular}

Table 11: List of frequently occurring DDIs base on it's severity

\begin{tabular}{|l|l|c|}
\hline Drug-Drug Interactions & Severity & Occurrence \\
\hline Fluconazole+Ondansetron & Major & 2 \\
\hline Octreotide+Ondansetron & Major & 2 \\
\hline Furosemide+Spironolactone & Moderate & 51 \\
\hline Propranolol+Furosemide & Moderate & 35 \\
\hline Propanolol+Spironolactone & Moderate & 32 \\
\hline Propranolol+Rifaximin & Moderate & 29 \\
\hline Phenytoin+Ondansetron & Moderate & 3 \\
\hline Propranolol+Amlodipine & Moderate & 2 \\
\hline Furosemide+Torsemide & Moderate & 2 \\
\hline Ceftriaxone+Furosemide & Minor & 62 \\
\hline Phenytoin+Furosemide & Minor & 2 \\
\hline
\end{tabular}

\section{DISCUSSION}

The study mainly focused on Drug Utilization pattern including analysis of the prescription, frequently used drugs and assessment of the pattern of co-morbidities associated with hepatic impairment patients. In our study, among 135 hepatic impairment patients, male were predominant to female with $83.70 \%$. It was also found that most of the patients $66 \%$ were between the age group of $40-59$ years, whereas result reported in Hyderabad, India ( Huma S. et al. $)^{8}$ were between the age group of $31-40$ years. The common co-morbid conditions were portal hypertension, anemia, hepatic encephalopathy, in contrast with the study conducted by Dhanya $\mathrm{H}$. et al. ${ }^{9}$ in which the frequently observed co-morbid were diabetes and hypertension. This suggests that alcohol intake, smoking and tobacco chewing could be the highest risk factor for the hepatic dysfunction.

In the study conducted by Zeebaish S. et al. ${ }^{10}$ showed drug utilization of diuretics prominently, which is similar to our study, which showed drug utilization of diuretics like furosemide, spironolactone. This was in contrast with the other study conducted by Alias BK. et al. ${ }^{11}$ in which antibiotics were prominent. Similarly, in the study of drug utilization of non-hepatospecific drugs antibiotics were prescribed frequently which is in contrast with the study conducted by Satish Kumar V. et al. ${ }^{12}$ in which anti-ulcer drugs were found to be major.

Drug Interaction is one of the very important issue in drug therapy, especially in patients with multiple medical conditions, like patients with hepatic impairment. In the present study, majority of the patients being admitted were between age group of 40-59 years and this age group were observed with more pDDIs $n=129(48.86 \%)$, in contrast with the study carried out by Sidra N. et al. ${ }^{13}$ where age group between 46-60 years had occurrence of DDIs. With the prevalence of polypharmacy increasing, it has become an important issue among patients with hepatic impairment ${ }^{14}$. Also, in our study, we observed significant association for presence of pDDIs with polypharmacy, longer hospital stay and comorbidities. These findings were in correlation with the study conducted by Sidra N. et al. ${ }^{13}$. From the analysis of 135 prescriptions, $8(0.03 \%)$ major, $180(68.18 \%)$ moderate and $76(28.78 \%)$ minor DDIs were identified. Identical results were observed in the study conducted by Gebretsadik Z. et al. ${ }^{15}$ In their study majority of the interactions were moderate 210 (59.5\%). Comorbid disease increases the prevalence of potential DDIs. And the reason for this might be the drug prescribed for the comorbid disease are often used in combination that can lead to possibility of the occurrence of potential DDIs. Moreover, increased hospital stay may also lead to occurrence of potential DDIs as hospitalized patients are more likely to exposed to multiple illness, polypharmacy, comorbid conditions and frequent modification of therapy ${ }^{16}$. In the study, the higher number of observed DDIs were due to pharmacodynamics interactions $(74.62 \%)$ compared to pharmacokinetic interactions (25.37\%). These findings were in accordance with the study conducted by Jigar Kapadia. et al. ${ }^{17}$.Therefore, the health care professionals should be well educated about the possible risk factors for potential DDIs in order to avoid or minimize potential DDIs in patients at high risk.

\section{CONCLUSION}

The study concludes that the epidemiological studies of hepatic impairment patients have shown the maximum prevalence of alcoholic liver disease followed by chronic liver disease. The utilization pattern of diuretics was more among hepatospecific drugs and antibiotics were utilized more among non-hepatospecific drugs. As in our study, antibiotics were the most prescribed drugs, the consequence of hepatotoxicity and antibiotic resistance is relatively high. So, there is need for improving prescribing pattern among the health care system.

Also, this study demonstrated high prevalence of potential drug-drug interaction (pDDIs) among males compared to females. The prevalence rate of pDDIs is directly related to length of stay, number of prescribed drugs and comorbidity conditions. The pharmacodynamics interaction was the common mechanism of pDDls. Thus, the development and implementation of guidelines and software based screening of pDDIs is recommended in order to help pharmacists and physicians to identify, prevent and manage pDDIs in hepatic impairment patients. 
Acknowledgement: We the authors would like to pass our gratitude for Chigateri District Hospital for their support during the study and the data collection.

Conflict of Interest: The authors declares that there is no conflict of interest regarding the publication of this article.

Ethical Approval: The study was approved by Hospital Ethical Committee of Chigateri District Hospital, Davanagere, Karnataka, India.

\section{REFERENCES}

1. Roger Walker, Cate Whittlesea. Clinical Pharmacy and Therapeutics", 5th edition, Edinburgh, London New York Oxford Philadelphia St Louis Sydney Toronto 2012. P. 238.

2. Asrani SK, Devarbhavi H, Eaton J, Kamath PS, Burden of liver diseases in the world. J Hepatol 2019;70:151-171.

3. 2014, http://apps.who.int/medicinedocs/en/d/Js4876e.

4. U. Bergman, I. Christenson, B. Jansson, and B. E. Wiholm, "Auditing hospital drug utilisation by means of defined daily doses per bed-day. A methodological study," European Journal of Clinical Pharmacology, 1980;17(3):183-187.

5. Tatro DS. Drug interaction facts 2008: the authority on drug interactions. Philadelphia, PA: Lippincott Williams \& Wilkins.

6. Jimmy OD, Shobha Rani RH, Indira R, Ramjan S. Study of drug-drug interactions charts in medicine wards at a tertiary care hospital, Bangalore. Indian J Pharm Press.2012;5(4);614.

7. Tannenbaum $\mathrm{C}$ and Sheehan NL. Understanding and preventing drug-drug and drug-gene interactions. Expert Rev Clin Pharmacol 2014; 7(4): 533-544.

8. Huma S, Fatima ON, Ayesha I, Moiz JM, Mohiuddin SM. Prescribing pattern of drugs used in chronic liver disease with co-morbid conditions and assessment of severity using MELD score. JDDT.2020:10(5-s):19-24.

9. Arathy.P.C, Vishak Mohan, Al-Muneer.S, Dhanya.A.H, "A Prospective and Observational study on pattern of comorbid conditions in CLD patients with Drug use pattern, and assessment of severity using MELD score". Indian Research Journal of Pharmacy and Science, 2016.

10. Zeebaish S, Hemalatha P, Eswari P, Kodandaraman T, Lakshmi P,Apoorva G. A prospective observational study on prescribing patternsof drugs used in alcoholic liver disease patients at tertiary care teaching hospital. International Journal of Basic \& Clinical Pharmacology. 2017June;6(6):1386-1392.

11. Alias BK, Sugali VN, Anusha S, Girish HN, Paparayudu G, Alekhya et al,. A prospective observational study to assess prescription pattern for various hepatic dysfunctions in a tertiary care teaching hospital. IOSR-JPBS.2019;14(5):34-40.

12. Sathish Kumar V, Bhavana $P$, Supriya.CH, Abdul Rahaman.SK, 'Prevalence and Drug Utilization Pattern in Hepatic Impairment Patients at a Tertiary Care Hospital". International Journal of Science and Research (IJSR).2017;6(7):1878-1882.

13. Noor S, Ismail M, Haider I, Khadim F. Drug-Drug interactions in hepatic patients. Do these interactions matter in clinical perspective? Annals of Hepatology.2018;17(6):100-1011.

14. Boccaccio V, Bruno S. Optimal management of patients with chronic hepatitis $C$ and comorbidities. Liver Int.2015; 35: 3543.

15. Gebretsadik Z, Gebrehans M, Getnet D, Gebrie D, Alema T, Belay YB. Assessment of Drug-Drug Interaction in Ayder Comprehensive Specialised Hopital, Mekella Northern Ethiopia: A Retrospective Study. BioMed research International, 2017.

16. Zwart-van-Rijkom JEF, Uijtendaal EV, Ten Berg MJ, Van Solinge WW, Egberts AC. Frequency and nature of drugdrug interactions in a Dutch university hospital. Br J Clin Pharmacol. 2009;68:187-93.

17. Kapadia J, Thakor D, Desai C, Dikshit RK. A study of potential drug-drug interactions in indoor patients of medicine department at tertiary care hospital. J Applied Pharm Sci.2013;3(10):89-96.

Source of Support: The author(s) received no financial support for the research, authorship, and/or publication of this article.

Conflict of Interest: The author(s) declared no potential conflicts of interest with respect to the research, authorship, and/or publication of this article.

For any question relates to this article, please reach us at: editor@globalresearchonline.net

New manuscripts for publication can be submitted at: submit@globalresearchonline.net and submit_ijpsrr@rediffmail.com 